\title{
CAESALPINIOIDEAE (LEGUMINOSAE) LENHOSAS NA ESTAÇÃO AMBIENTAL DE VOLTA GRANDE, MINAS GERAIS, BRASIL ${ }^{1}$
}

\author{
Fabiana Luiza Ranzato Filardi², Flávia Cristiana Pinto Garcia ${ }^{3}$ e Rita Maria de Carvalho Okano ${ }^{3}$
}

\begin{abstract}
RESUMO - Este trabalho apresenta o levantamento florístico das Caesalpinioideae lenhosas nas formações de Cerrado e de Floresta Semidecidual, da Estação Ambiental de Volta Grande. A área de estudo, localizada no Triângulo Mineiro, faz parte do complexo da Usina Hidrelétrica Estadual de Volta Grande, reúne 391 ha e retrata 30 anos de regeneração natural. Foram registrados 14 táxons da subfamília, reunidos em 11 gêneros e quatro tribos. Caesalpinieae foi a tribo mais representada (Dimorphandra Schott, Diptychandra Tul, Peltophorum (Vogel) Benth., Pterogyne Tul. e Tachigali Aubl.), seguida por Cassieae (Apuleia Mart., Chamaecrista Moench e Senna Mill.), Detarieae (Copaifera L. e Hymenaea L.) e Cercideae (Bauhinia L.). O gênero mais representativo foi Senna (4 spp.), enquanto os demais foram representados por uma espécie cada. Apresentam-se chave para identificação, descrições e ilustrações, além de comentários sobre a distribuição geográfica dos táxons encontrados.
\end{abstract}

Palavras-chave: Florística, Cerrado e Triângulo Mineiro.

\section{WOODY CAESALPINIOIDEAE (LEGUMINOSAE) SPECIES AT THE ESTAÇÃO AMBIENTAL DE VOLTA GRANDE, MINAS GERAIS, BRAZIL.}

\begin{abstract}
This work presents the floristic survey of woody Caesalpinioideae taxa in the "Cerrado" and Semideciduous Forest vegetation, at the Estação Ambiental de Volta Grande. The area of study is located in the Triângulo Mineiro and belongs to the Companhia Energética de Minas Gerais. It covers 391 ha and represents 30 years of natural regeneration. Fourteen taxa were reported for the subfamily, distributed in 11 genera and four tribes. Caesalpinieae was the most representative tribe (Dimorphandra Schott, Diptychandra Tul., Peltophorum (Vogel) Benth., Pterogyne Tul. and Tachigali Aubl.), followed by Cassieae (Apuleia Mart., Chamaecrista Moench and Senna Mill.), Detarieae (Copaifera L. and Hymenaea L.) and Cercideae (Bauhinia L.). The most representative genus was Senna (4 spp.). Each one of the others was represented by one species. Identification key, descriptions and illustrations are presented for the sampled taxa, besides comments about their geographical distribution.
\end{abstract}

Keywords: Floristic, Cerrado and Triângulo Mineiro.

\section{INTRODUÇÃO}

O Cerrado cobre aproximadamente $2.000 .000 \mathrm{~km}^{2}$, que abrangem mais de $20^{\circ}$ de latitude (COUTINHO, 2002), figurando entre os ecossistemas mais diversos e ameaçados do planeta (MYERS et al., 2000). Com diversidade florística estimada em 10.000 espécies, sendo 4.400 delas endêmicas, os remanescentes de vegetação primária do Cerrado correspondem somente a $20 \%$ de sua área original, e apenas $6,2 \%$ estão localizados em áreas de preservação (MYERS et al.,
2000). A vegetação do Cerrado caracteriza-se pela existência de fitofisionomias ecotonais entre dois extremos fisionômicos, o Cerradão, onde predominam o componente arbustivo-arbóreo e o campo limpo, com predomínio do componente herbáceosubarbustivo (COUTINHO, 2002).

Leguminosae é considerada uma das famílias de maior riqueza florística do bioma, reunindo $25 \%$ dos táxons, com representantes herbáceos e lenhosos, juntamente com Asteraceae (16\%), Orchidaceae (14\%)

\footnotetext{
${ }^{1}$ Recebido em 25.04.2008 e aceito para publicação em 23.06.2009.

${ }^{2}$ Programa de Pós-Graduação em Botânica do Instituto de Pesquisa Jardim Botânico do Rio de Janeiro e-mail: <ffilardi@jbrj.gov.br>.

${ }^{3}$ Departamento de Biologia Vegetal da UFV, Viçosa-MG. E-mail:<fcgarcia@ufv.br> e <carvalho@ufv.br>.
} 
e Poaceae (11\%), famílias inexpressivas para o estrato arbustivo-arbóreo (MENDONÇA et al., 1998). Portanto, Leguminosae é importante para a dinâmica das comunidades nas diferentes fitofisionomias que compõem o Cerrado: campo limpo, campo sujo, campo cerrado, cerrado sensu stricto e cerradão (EITEN, 1972; MENDONÇA et al., 1998). A família apresenta altos índices de valor de importância (IVI) em estudos sobre estrutura de comunidades realizados em áreas do bioma (MEIRA NETO e SAPORETTI JÚNIOR, 2002; SAPORETTI JÚNIOR et al., 2003), além de reunir espécies pioneiras que viabilizam a sucessão em áreas degradadas (ARAÚJO et al., 2005).

Para a subfamília Caesalpinioideae são reconhecidas cerca de 2.250 espécies, pertencentes a 161 gêneros e quatro tribos: Caesalpinieae, Cassieae, Cercideae e Detarieae (LEWIS et al., 2005), sendo citados 240 táxons para o Cerrado (MENDONÇA et al., 1998). Caesalpinioideae reúne principalmente representantes arbóreos e arbustivos, de ocorrência nas regiões tropicais e subtropicais, cujas características principais são: folhas pinadas ou bipinadas, cálice geralmente dialissépalo, corola actinomorfa, zigomorfa ou assimétrica, dialipétala e com prefloração imbricada carenal (POLHILL e RAVEN, 1981; LEWIS et al., 2005).

Originalmente, o Cerrado cobria toda a porção centro-ocidental de Minas Gerais, contudo, principalmente no Triângulo Mineiro, imensas áreas foram desmatadas para dar lugar à agropecuária e à monocultura. A Estação Ambiental de Volta Grande (EAVG), após 30 anos de regeneração natural, apresenta-se como uma das poucas áreas protegidas da região de Uberaba, que, segundo DRUMMOND et al., (2005), seria prioritária para a conservação e a investigação científica no Estado, pois apresenta alta importância biológica, alto grau de fragilidade e número reduzido de unidades de conservação.

Estudos específicos sobre Leguminosae em Minas Gerais estão restritos principalmente a áreas de Mata Atlântica (MENDONÇA FILHO, 1996; BORTOLUZZI et al., 2004; LIMA et al., 2007; RODRIGUES e GARCIA, 2007) e dos campos rupestres (QUEIROZ, 2004; DUTRA et al., 2008; FILARDI et al., 2007a). Devido à importância da família para o Cerrado, este trabalho teve como objetivo estudar os representantes lenhosos da subfamília Caesalpinioideae na EAVG, a única área de compensação ambiental da Companhia Energética de Minas Gerais (CEMIG) implantada em conjunto com o complexo industrial de produção de energia. Fazem parte do trabalho uma chave analítica para a identificação dos táxons, descrições, ilustrações e citações de nomes populares, além de comentários sobre distribuição geográfica e preferência por hábitat na EAVG.

\section{MATERIAL E MÉTODOS}

AEAVG faz parte do complexo da Usina Hidrelétrica Estadual de Volta Grande, que pertence à CEMIG e localiza-se a $40 \mathrm{~km}$ de Uberaba, entre os Municípios de Conceição das Alagoas (MG) e Miguelópolis (SP) $\left(20^{\circ} 00^{\prime}-20^{\circ} 01^{\prime} \mathrm{S}\right.$ e $\left.48^{\circ} 12^{\prime}-48^{\circ} 15^{\prime} \mathrm{W}\right)$. Nessa região, o clima é do tipo Cwa, de acordo com a classificação de Köppen, com temperatura média anual entre 22 ${ }^{\circ} \mathrm{C}$ e $24^{\circ} \mathrm{C}$, estação seca bem definida, de maio a outubro, e precipitação média anual de $1.550 \mathrm{~mm}$ (CPTEC/INPE, 2006). Criada em 1976, a EAVG reúne 391 ha, e cerca de 190 ha de Cerrado e 85 ha de Floresta Estacional Semidecidual encontram-se em franco processo de sucessão secundária, abrigando ainda 30 ha de várzea (FILARDI et al., 2007b).

Foram realizadas 10 expedições para a coleta de material botânico, entre setembro de 2002 e novembro de 2005. Com a finalidade de cobrir a variação fisionômica da vegetação, foram estabelecidas seis trilhas em formações de Cerrado e quatro em áreas de Floresta Estacional Semidecidual. A trilha 1 representa a área de Cerrado sensu stricto em estágio de regeneração mais avançado, com cerca de 60 ha, e as trilhas 2, 3 e 4 representam áreas mais alteradas de Cerrado sensu stricto, enquanto as trilhas 5 e 6 são manchas de Cerradão, que reúnem aproximadamente 16 ha. Nas formações de Floresta Estacional Semidecidual, as trilhas 7 e 8 são adjacentes à área de várzea, enquanto as trilhas 9 e 10 se localizam nas margens mineira e paulista do reservatório, respectivamente (FILARDI et al., 2007b).

O material botânico foi coletado e herborizado conforme as técnicas de FIDALGO e BONONI (1984), registrado e incorporado ao acervo do Herbário VIC, do Departamento de Biologia Vegetal da Universidade Federal de Viçosa. A terminologia morfológica adotada nas descrições seguiu os trabalhos de RADFORD et al. (1974); POLHILL e RAVEN (1981) e BARROSO et al., (1999) e a classificação adotada para tribos e gêneros foi a de LEWIS et al. (2005). A chave para identificação dos táxons, bem como as descrições 
e ilustrações, foi elaborada apenas com base no material coletado na EAVG, sendo os táxons apresentados em ordem alfabética. Comentários sobre a distribuição geográfica dos táxons foram obtidos a partir de revisões dos gêneros estudados e do International Legume Database and Information Service (ILDIS, 2007). As ilustrações das características vegetativas e reprodutivas foram realizadas a partir de materiais herborizados e, ou, fixados em álcool 70\%, com o auxílio de uma câmara clara acoplada a um estereomicroscópio Olympus.

\section{RESULTADOS E DISCUSSÃO}

Foram identificados 14 táxons de Caesalpinioideae, pertencentes a 11 gêneros, representantes das quatro tribos: Caesalpinieae (Dimorphandra Schott, Diptychandra Tul., Peltophorum (Vogel) Benth., Pterogyne Tul. e Tachigali Aubl.), Cassieae (Apuleia Mart., Chamaecrista Moench e Senna Mill.), Detarieae (Copaifera L. e Hymenaea L.) e Cercideae (Bauhinia L.). O gênero mais expressivo foi Senna (4 spp.), enquanto os demais foram representados por uma espécie cada. A maioria dos táxons (79\%) apresenta hábito arbóreo, e apenas três deles têm hábito arbustivo, e todos já foram citados para a flora do Cerrado (MENDONÇA et al., 1998; RATTER et al., 2003).

Apesar de a área estudada apresentar apenas 391 ha, o número encontrado de táxons lenhosos foi expressivo, quando comparado com os obtidos em levantamentos realizados em municípios mineiros pertencentes ao bioma Cerrado, a exemplo de Uberaba com 14 espécies e sete gêneros (BRANDÃO et al., 1995), Prudente de Morais com 16 espécies e seis gêneros (BRANDÃO et al., 1996) e Sete Lagoas com 16 espécies e oito gêneros (BRANDÃO et al., 1993).

Na EAVG, a maioria dos táxons $(57 \%)$ se mostrou restrita às áreas de Cerrado sensu stricto, $29 \%$ deles foram coletados tanto em formações de Cerrado quanto de Floresta Semidecidual e 14\% ocorreram apenas nas áreas de floresta. Na área de estudo foram introduzidos oitos táxons lenhosos de Caesalpinioideae, não tratados neste trabalho: Bauhinia variegata L., Caesalpinia pluviosa DC. var. pelthophoroides (Benth.) G. P. Lewis, C. ferrea Mart. ex Tul., Cassia fistula L., C. grandis L., C. javanica L., Delonix regia (Bojer ex Hook.) Raf. e Tamarindus indica $\mathrm{L}$.

\subsection{Chave para identificação das Caesalpinioideae lenhosas da EAVG}

1. Folhas unifolioladas 2. Bauhinia rufa

1'. Folhas 2-plurifolioladas.

2. Folhas bipinadas.

3. Foliólulos opostos, 2-3,8 mm larg.; panícula de racemos; corola zigomorfa; fruto legume samaróide var.dubium

8. Peltophorum dubium

3'. Foliólulos alternos a subopostos, 4-7 mm larg.; panícula de espigas; corola actinomorfa; fruto legume 5. Dimorphandra mollis

2'. Folhas pinadas.

4. Folhas imparipinadas.

5. Raque foliar com apêndice terminal; fruto sâmara, região seminífera proximal ..... 9. Pterogyne nitens

5'. Raque foliar sem apêndice terminal; fruto legume samaróide, região seminífera central

1.Apuleia leiocarpa

4'. Folhas paripinadas.

6. Nectários foliares ausentes.

7. Folíolos 1 par . 7. Hymenaea martiana

7'. Folíolos 3 ou mais pares.

8. Folíolos glabros, com pontuações translúcidas.

9. Folíolos alternos ou subopostos; pétalas ausentes; sementes com arilo, não aladas 4. Copaifera langsdorffii

9’. Folíolos opostos; pétalas presentes; sementes sem arilo, aladas.

\section{..6. Diptychandra aurantiaca ssp. aurantiaca}

8'. Folíolos pilosos, sem pontuações translúcidas.

10. Ápice do folíolo caudado; corola actinomorfa, creme; anteras isomórficas

\section{Tachigali rubiginosa}

10'. Ápice do folíolo agudo; corola zigomorfa, amarela; anteras heteromórficas

\section{Senna silvestris var. bifaria}

6'. Nectários foliares presentes.

11. Nectários presentes entre mais de um par de folíolos.

R. Árvore, Viçosa-MG, v.33, n.6, p.1071-1084, 2009 
12. Folíolos 2 pares, uniformemente indumentados na face abaxial; anteras heteromórficas

\section{Senna macranthera}

12'. Folíolos 4-5 pares, indumento apenas sobre a nervura mediana na face abaxial; anteras isomórficas 3. Chamaecrista ensiformis var. ensiformis

11'. Nectário presente somente entre os folíolos do par proximal ou do par distal.

13. Folíolos 4-5 pares, raque $1,5-3,6 \mathrm{~cm}$ compr., nectário entre os folíolos do par proximal 12. Senna pendula var. glabrata

13'. Folíolos 10-12 pares, raque 30-43 cm compr., nectário entre os folíolos do par distal.

10. Senna alata

\section{2. Descrição dos táxons lenhosos de Caesalpinioideae encontrados na EAVG}

1. Apuleia leiocarpa (Vogel) J.F. Macbr., Contrib. Gray Herb. 59: 23. 1919. Figuras 1-2

Nome popular: Garapa

Árvores ca. $10 \mathrm{~m}$ alt.; ramos lenticelados, glabrescentes. Folhas imparipinadas; estípulas oblanceoladas, ca. $5 \mathrm{~mm}$ compr., caducas; pecíolo 1-1,6 cm compr., puberulento; raque 5,6-10,3 cm compr., puberulenta; folíolos 7-13,3,56,3x1,4-2,7 cm, alternos, elípticos, base obtusa, ápice obtuso a levemente retuso, face adaxial esparsamente tomentosa a glabrescente, face abaxial tomentosa. Flores não observadas. Legumes samaróides, 5,8-6,5x1,2-1,5 $\mathrm{cm}$, elípticos a irregularmente ovados, região seminífera central, base aguda, ápice obtuso, tomentosos, castanhos; sementes 1-2, exariladas.

Material examinado - BRASIL. Minas Gerais: EAVG, trilha 9, IX/2002 (fr.), Filardi et al. 140 (VIC).

Amplamente distribuída na América do Sul (ILDIS, 2007), no Brasil ocorre do Pará ao Rio Grande do Sul (OLIVEIRA-FILHO, 2006), sendo citada para áreas de Caatinga, Cerrado e Mata Atlântica (LEWIS, 1987). Segundo OLIVEIRA-FILHOeFONTES (2000), A. leiocarpa é característica de florestas semidecíduas do Sudeste do Brasil. Na EAVG, a espécie é pouco frequente e ocorre apenas nas matas da margem mineira do reservatório.

2. Bauhinia rufa (Bong.) Steud., Nom. Bot., ed.2, 1: 192. 1840. Figuras 3-4

R. Árvore, Viçosa-MG, v.33, n.6, p.1071-1084, 2009
Nome popular: Pata-de-vaca, unha-de-vaca

Arbustos com 0,4-1 m de alt.; ramos angulosos, canaliculados, velutino-ferrugíneos. Folhas unifolioladas; estípulas lineares, ca. de $1 \mathrm{~mm}$ de compr.; pecíolo de 1-2 cm de compr., tomentoso, nectários subuliformes; folíolos bilobados, lobos concrescidos de 2/3 a $3 / 4$ do compr., 5,5-13x5-11,8 cm, alternos, cordiformes, base cordada, ápice obtuso a subtruncado, face adaxial glabra, face abaxial tomentosa-ferrugínea, 9-11 nervuras principais. Inflorescências pseudo-racemosas, pedúnculo de 1,5-5 cm de compr., raque de 10-15 cm de compr., tomentosa. Flores zigomorfas; pedicelo de 2-2,5 cm compr.; cálice de 4-5-laciniado, sépalas de 5-7,5 cm de compr., tomentosas; pétalas branco-esverdeadas, lineares, 3,5-4,6x0,1-0,2 cm; estames 10, 5-6,5 cm de compr., filetes glabros, anteras rimosas, isomórficas; ovário ca. de $2 \mathrm{~cm}$ de compr., tomentoso, estípite ca. de 3,5 cm de compr., estilete ca. de $2 \mathrm{~cm}$ compr. e estigma clavado. Legumes de 17-24,5x1,5-2 cm, estreitamente oblongos, estípite de 3,3-5 cm de compr., base atenuada, ápice agudo; tomentosos, castanho-escuros, valvas de deiscência espiralada; sementes 6-18, exariladas.

Material examinado - BRASIL. Minas Gerais: EAVG, trilha 1, V/2005 (fr), Filardi et a.l 573 (VIC); 577 (VIC); trilha 2, IX/2002 (fr.), Filardi et al. 73 (VIC); II/2003 (fr.), Filardi et al. 212 (VIC); XII/2003 (fl.), Filardi et al. 413 (VIC); III/2004 (fr.), Filardi et al. 439 (VIC); trilha 3, III/2004 (fl., fr.), Filardi et al. 458 (VIC).

Nativa do Brasil, ocorre no Cerrado e em campos rupestres da Cadeia do Espinhaço, sendo citada para Distrito Federal, Goiás, Minas Gerais (VAZ e TOZZI, 2003), Bahia (ZAPPI et al., 2003) e São Paulo (DURIGAN et al., 2004). Segundo Rizzini (1963), a espécie faz parte da flora lenhosa peculiar do Cerrado e na EAVG mostrouse frequente e restrita às áreas de Cerrado sensu stricto.

3. Chamaecrista ensiformis var. ensiformis (Vell.) H. S. Irwin \& Barneby, Mem. New York Bot. Gard. 35 (2): 642. 1982. Figuras 5-7

\section{Nome popular: Jaúna}

Árvores ca. de $5 \mathrm{~m}$ de alt.; ramos esparsamente lenticelados, glabros. Folhas paripinadas; estípulas não observadas; pecíolo com 2,4-4 cm de compr., glabro; raque com 9-11,5 cm de compr., glabra, nectários 
pateliformes entre todos os pares de folíolos; folíolos com 4-5 pares (4,5-)5-10(-12,5)x2-5 cm, opostos, elípticos a oblongos, base obtusa a cuneada, ápice agudo, face abaxial com nervura mediana pilosa. Inflorescências racemosas, ramifloras, pedúnculo com 2,7-7 cm de compr., raque com 1,8-3 cm de compr., tomentosa. Flores assimétricas; pedicelo com 2-3 cm de compr.; cálice 5-laciniado, sépalas com 5-6×2-3 mm, ciliadas; pétalas amarelas, com 9-13x8-11 mm, base atenuada, ápice obtuso; estames 10, ca. de $6 \mathrm{~mm}$ de compr., filetes glabros, anteras poricidas, isomórficas; ovário ca. de $7 \mathrm{~mm}$ de compr., viloso, excêntrico, estípite ca. de $2 \mathrm{~mm}$ de compr., estilete ca. de $8 \mathrm{~mm}$ de compr., estigma crestado. Frutos não observados.

Material examinado - BRASIL. Minas Gerais: EAVG, trilha 2, III/2004 (fl.), Filardi et al. 466 (VIC).

Variedade restrita ao Brasil e presente, principalmente, nos Estados do Amazonas, Bahia, Goiás, Maranhão, Mato Grosso, Pará e Rio de Janeiro (IRWIN e BARNEBY, 1982). Chamaecrista ensiformis é característica do Brasil Atlântico Nordeste-Sudeste-Sul (MORIM, 2006), sendo citada para formações de restinga, Mata Atlântica (LEWIS, 1987) e Cerrado (MENDONÇA et al., 1998; OLIVEIRA-FILHO, 2006). A espécie apresenta potencial para a recuperação de áreas degradadas, pois é capaz de estabelecer associação com bactérias para fixação de nitrogênio (SPRENT, 2001). Na EAVG, o táxon é pouco frequente e foi coletado apenas em uma das áreas de Cerrado sensu stricto.

4. Copaifera langsdorffii Desf., Mem. Mus. Paris 7: 377. 1821. Figuras 8-9

Nome popular: Copaíba, óleo-de-copaíba

Árvores de 7-10 m de alt.; ramos esparsamente lenticelados, glabrescentes. Folhas paripinadas; estípulas não observadas; pecíolo de 0,6-2 cm de compr., puberulento; raque (3,5-)4-10 cm de compr., puberulenta; folíolos (3-)4-5 pares, (2-)3-6,5(-7,3)x1,2-3,5 cm, alternos ou subopostos, elípticos a oblongo-elípticos, base obtusa ou oblíqua, ápice agudo, levemente retuso, glabros, pontos translúcidos na lâmina. Inflorescências em panículas racemosas, pedúnculo com 5-13 mm de compr., raque com 6,2-8,4 cm de compr., tomentosa. Flores monoclamídias, pedicelo ca. de $1 \mathrm{~mm}$ de compr.; cálice 4-laciniado, sépalas de 4-5x1,5-3 mm, internamente seríceas, externamente verrucosas, glabras; pétalas ausentes; estames 10, 4,5-6 mm de compr., filetes glabros, anteras rimosas, isomórficas; ovário ca. de $2 \mathrm{~mm}$ de compr., tomentoso, estípite ca. de 0,5 mm de compr., estilete ca. de 4,5 mm de compr., estigma lobado. Legumes de 3-3,2x2,2-2,5 cm, orbiculares, estípite de 2-3 mm de compr., base obtusa, ápice agudo, glabros, amarelados a castanhos quando maduros; monospérmicos, sementes ariladas, arilo carnoso róseo-avermelhado.

Material examinado - BRASIL. Minas Gerais: EAVG, trilha 1, I/2003 (fl.), Filardi 178 \& Faria (VIC); II/2003 (fr.), Filardi et al. 248(VIC); IX/2003 (fr.), Filardi et al. 330 (VIC); trilha 2, IX/2002 (fr.), Filardi et al. 76 (VIC); trilha 8, IX/2003 (fr.) e Filardi et al. 321 (VIC).

Espécie amplamente distribuída no Brasil centrooriental (MORIM, 2006), ocorre na Bahia (LEWIS, 1987; ZAPPI et al., 2003), Goiás, Minas Gerais, Paraná, São Paulo e Rio de Janeiro (DWYER, 1951), ocupando tanto formações florestais quanto campestres (QUEIROZ, 2004; MENDONÇA et al., 1998). Copaifera langsdorffii é característica de Florestas Semidecíduas da Região Sudeste do Brasil (OLIVEIRA-FILHO e FONTES, 2000). Na EAVG, a espécie é frequente e ocupa tanto áreas de Cerrado sensu stricto quanto de floresta associada à área de várzea.

5. Dimorphandra mollis Benth., J. Bot. (Hooker) 2 (10): 102. 1840. Figuras 10-12

\section{Nome popular: Faveira}

Árvores com 5-8 m de alt.; ramos angulosos, canaliculados, tomentoso-ferrugíneos. Folhas bipinadas; estípulas não observadas; pecíolo com 3-5 cm de compr., tomentoso; raque com 16,5-28,5 cm de compr., tomentosa; pinas 10-17 pares, opostas a subopostas; raque da pina (6-)9-13(-14) cm de compr., tomentosa; foliólulos (10-)17-24(-27) pares por pina, 7-18x4-7 mm, alternos a subopostos, oblongos a elípticos, base truncada a obtusa, ápice obtuso, tomentoso-ferrugíneos. Inflorescências em panículas de espigas, pedúnculo com 1,7-2,6 cm de compr., raque com 4,5-5,6 cm de compr., tomentosa. Flores actinomorfas; cálice 5-laciniado, sépalas ca. de $2 \times 1 \mathrm{~mm}$, verrucosas, tricomas esparsos; pétalas amarelas, 3x1,2-1,5 mm, base atenuada, ápice obtuso a truncado; estames 5, ca. de 3,2 mm de compr., filetes glabros, anteras rimosas, isomórficas, 5 estaminódios alternados com os estames; ovário ca. de $2 \mathrm{~mm}$ de compr.,

R. Árvore, Viçosa-MG, v.33, n.6, p.1071-1084, 2009 
glabro, estípite ca. de $0,5 \mathrm{~mm}$ de compr., estilete ca. de $1 \mathrm{~mm}$ de compr., estigma apical. Legumes de 13-14x3 cm, oblongos, estípite 1-1,5 cm de compr., base atenuada, ápice obtuso, glabros, castanhoescuros; 10-15 sementes, exariladas.

Material examinado - BRASIL. Minas Gerais: EAVG, trilha 2, XII/2003 (fr.), Filardi et al. 372 (VIC); III/2004 (fl.), Filardi et al. 457 (VIC); trilha 3, I/2003 (fl.), Filardi 166 \& Faria (VIC); II/2003 (fr.) e Filardi et al. 197 (VIC).

Ocorre na Bolívia, Paraguai e Brasil (ILDIS, 2007), onde é citada como característica do bioma Cerrado (RIZZINI, 1963; SILVA, 1986; RATTER et al., 2003), podendo ser utilizada para recuperação de áreas degradadas, pois é capaz de estabelecer associação com bactérias para fixação de nitrogênio (SPRENT, 2001). Na EAVG, a espécie é abundante, principalmente nas áreas mais alteradas de Cerrado sensu stricto.

\section{Diptychandra aurantiaca subsp. aurantiaca} Tul., Ann. Sci. Nat. (Paris). 2º ser. 20: 139. 1843. Figuras 13-16

Nome popular: Bálsamo-do-cerrado, carvãovermelho

Árvores com 8-10 m de alt.; ramos lenticelados, suberosos, glabros. Folhas paripinadas; estípulas não observadas; pecíolo com 1,4-3 cm de compr., glabro; raque (5,5-)6-8,5 cm de compr., glabra; folíolos de 3-6 pares, 2,6-5 (-6,5)x1,2-3,2 cm, opostos, elípticos ou ovados, base obtusa, ápice acuminado, glabros, pontos translúcidos na lâmina. Inflorescências racemosas, pedúnculo com 1,74,4 cm de compr., raque de $9-13,3 \mathrm{~cm}$ de compr., esparsamente tomentosa. Flores actinomorfas; pedicelo com 6-10 mm de compr.; cálice 5-laciniado, sépalas com 3,5-5 x2,5-3 mm, puberulentas, com pontuações amareladas; pétalas branco-amareladas; de 4,5-6x3,5 mm, base truncada, ápice obtuso; estames 10, 5-6 mm de compr., filetes pilosos, anteras rimosas, isomórficas; ovário ca. de $2 \mathrm{~mm}$ de compr., esparsamente tomentoso, estípite ca. de $1,5 \mathrm{~mm}$ de compr., estilete ca. $4 \mathrm{~mm}$ de compr., estigma lobado. Legumes com 6,5-16x2,8-3,1 cm, elípticos, estípite ca. de $5 \mathrm{~mm}$ de compr., base e ápice obtusos, glabros, castanho-claros; sementes 1 (-2), exariladas, aladas.

R. Árvore, Viçosa-MG, v.33, n.6, p.1071-1084, 2009
Material examinado - BRASIL. Minas Gerais: EAVG, trilha 1, XI/2005 (fl), Filardi 693 \& Garcia (VIC); trilha 2, II/2003 (fr.), Filardi et al. 218 (VIC); XII/2003 (fl.), Filardi et al. 394 (VIC); trilha 3, XII/2003 (fl., fr.) e Filardi et al. 409 (VIC).

Restrita ao Brasil, a subespécie aurantiaca distribuise pelo Cerrado nos Estados de Goiás, Mato Grosso do Sul, Minas Gerais (LIMA et al., 1987) e São Paulo (DURIGAN et al., 2004), fazendo parte da flora lenhosa peculiar do bioma (RIZZINI, 1963). Na EAVG, o táxon é pouco frequente, mas ocorre tanto na área em estágio de regeneração mais avançado (trilha 1) quanto nas áreas mais alteradas de Cerrado sensu stricto.

7. Hymenaea martiana Hayne, Arzneik. gebräuchl. Gewächses 11: pl. 15. 1830. Figuras 17-19

Nome popular: Jatobá

Árvores ca. de $12 \mathrm{~m}$ de alt.; ramos cilíndricos, lenticelados, vilosos. Folhas paripinadas; estípulas não observadas; pecíolo com 11-15 mm de compr., velutino; folíolos 1 par, 6-8x2,5-3,5 cm, opostos, elípticos a obovados, base oblíqua, ápice obtuso, face adaxial glabrescente, áspera, face abaxial densamente tomentosa. Inflorescências em panículas de corimbos, pendúnculo com 1,2-2 cm de compr., raque com 2-3 cm de compr., tomentosa. Flores actinomorfas; pedicelo ca. de $17 \mathrm{~mm}$ de compr.; cálice 4-laciniado, sépalas de 16-17x10-18 $\mathrm{mm}$, internamente seríceas, externamente verrucosas, tomentosas; pétalas brancas de 17-19x10-13 mm, base truncada, ápice obtuso, pontos resiníferos; estames 10 , ca de $2 \mathrm{~cm}$ de compr., filetes glabros, anteras rimosas, isomórficas; ovário ca. de $8 \mathrm{~mm}$ de compr., viloso na base, estípite ca. de $6 \mathrm{~mm}$ de compr., estilete ca. 15 mm compr., estigma capitado. Legumes nucóides, 6,58x3,5-4,3 cm, oblongo-cilíndricos, estípite ca. 6 mm compr., base e ápice obtusos, glabros, enegrecidos; sementes 4-6, ariladas, arilo farináceo, branco.

Material examinado - BRASIL. Minas Gerais: EAVG, trilha 1, IX/2002 (bo. fl.), Filardi et al. 153 (VIC); II/2003 (fr.) e Filardi et al. 233 (VIC).

Restrita à América do Sul (ILDIS, 2007), no Brasil ocorre nas Regiões Nordeste, Centro-Oeste e Sudeste, ocupando áreas de caatinga e cerrado (LEE e LANGENHEIM, 1975). Na EAVG, a espécie é pouco frequente e restrita à área de Cerrado sensu stricto em estágio mais avançado de regeneração. 
Fonte: Ilustrações de Reinaldo A. Pinto. Source: Illustrated by Reinaldo A. Pinto.

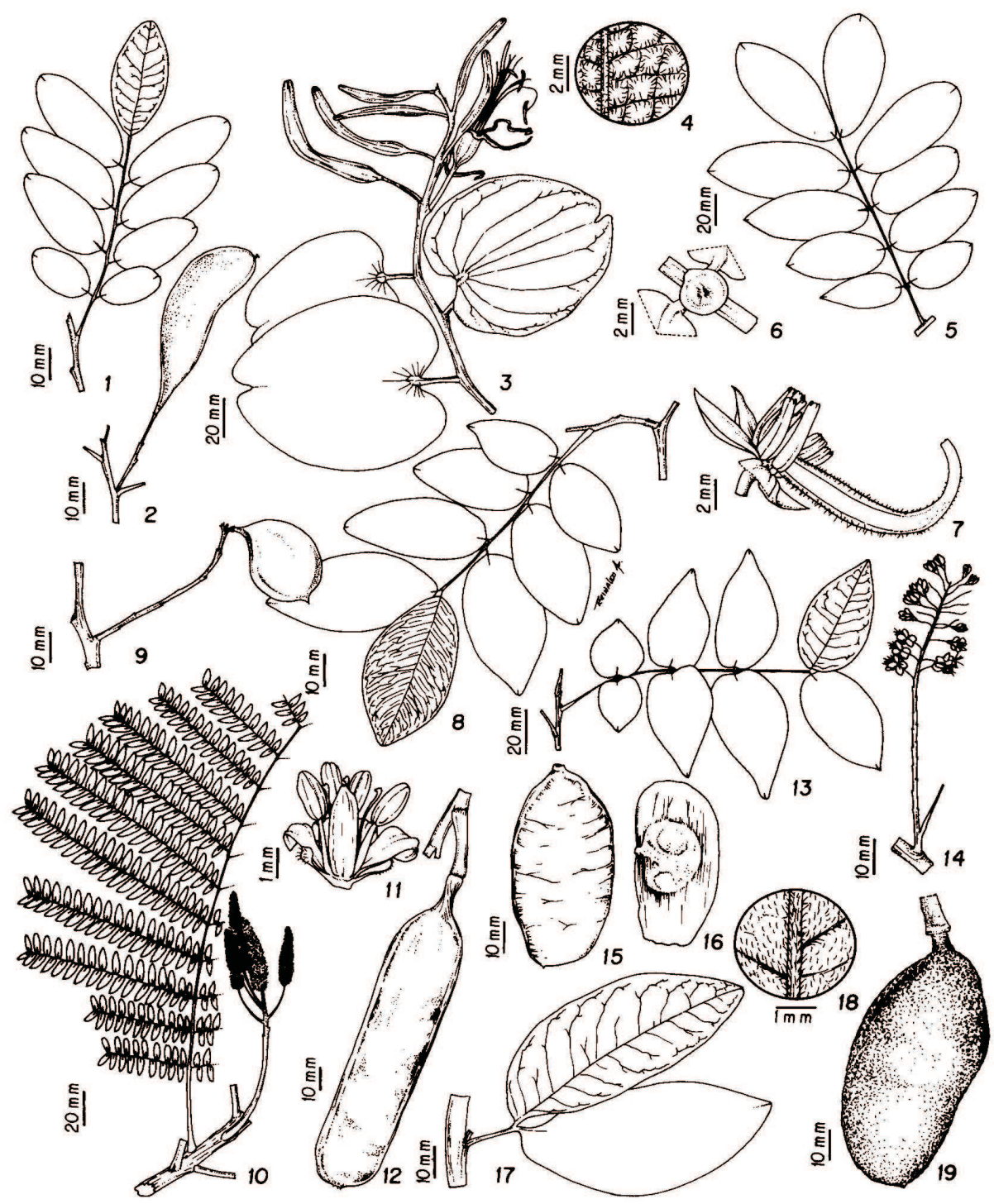

Figura 1 -Apuleia leiocarpa: 1. Folha, 2. Fruto (Filardi et al. 140). Figuras 3-4. Bauhinia rufa: 3. Ramo floral, 4. Indumento na face abaxial da folha (Filardi et al. 413). Figuras 5-7. Chamaecrista ensiformis var. ensiformis: 5. Folha, 6. Nectário extrafloral, 7. Androceu e gineceu (Filardi et al. 466). Figuras 8-9. Copaifera langsdorffii: 8. Folha, 9. Fruto (Filardi et al. 76). Figuras 10-12. Dimorphandra mollis: 10. Ramo floral, 11. Flor em corte longitudinal (Filardi et al. 457), 12. Fruto (Filardi et al. 372). Figuras 13-16. Diptychandra aurantiaca subsp. aurantiaca: 13. Folha, 14. Inflorescência (Filardi et al. 394), 15. Fruto, 16. Semente (Filardi et al. 409). Figuras 17-19. Hymenaea martiana: 17. Folha, 18. Indumento na face abaxial do folíolo, 19. Fruto (Filardi et al. 233).

Figures 1-Apuleia leiocarpa: 1. Leaf, 2. Fruit (Filardi et al. 140). Figures 3-4. Bauhinia rufa: 3. Floral branch, 4. Indummentum of leaf abaxial face (Filardi et al. 413). Figures 5-7. Chamaecrista ensiformis var. ensiformis: 5. Leaf, 6. Extrafloral nectaries, 7. Androecium and gynoecium (Filardi et al. 466). Figures 8-9. Copaifera langsdorffii: 8. Leaf, 9. Fruit (Filardi et al. 76). Figures 10-12. Dimorphandra mollis: 10. Floral branch, 11. Flower in longitudinal view (Filardi et al. 457), 12. Fruit (Filardi et al. 372). Figures 13-16. Diptychandra aurantiaca subsp. aurantiaca: 13. Leaf, 14. Inflorescence (Filardi et al. 394), 15. Fruit, 16. Seed (Filardi et al. 409). Figures 17-19. Hymenaea martiana: 17. Leaf, 18. Indummentum of leaflet abaxial face, 19. Fruit (Filardi et al. 233). 
8. Peltophorum dubium var. dubium (Spreng.) Taub., Engl. \& Prantl, Natürl. Pflanzenfam. 3 (3): 176. 1892. Figura 20

Nome popular: Canafístula, angico-cangalha

Árvores 6-7 m alt.; ramos canaliculados, lenticelados, tomentoso-ferrugíneos. Folhas bipinadas; estípulas fimbriadas, ca. de $8 \mathrm{~mm}$ de compr., caducas; pecíolo (2-)2,5-5(-5,8) cm de compr., tomentoso; raque (12-)1525(-28) cm de compr, tomentosa; pinas (9-)11-22 pares, opostas a subopostas; raque da pina (4-)5,8-8,5(-9,5) cm de compr., tomentosa; foliólulos 19-29(-32) pares por pina, (5-)6-12x2-3,8 mm, opostos, oblongos, base oblíqua, ápice obtuso, face adaxial glabrescente, face abaxial tomentosa. Inflorescências em panículas racemosas, pedúnculo 2,1-3 cm de compr., raque com 11-18 cm de compr., tomentosa. Flores zigomorfas; pedicelo com 7-9 mm de compr.; cálice 5-laciniado, sépalas com 7-10x3-6 mm, internamente pilosas, externamente puberulentas; pétalas amarelas, a centro-adaxial 1-1,6x1$1,5 \mathrm{~cm}$, as latero-adaxiais $1,3-1,6 \times 1,1-1,5 \mathrm{~cm}$, as abaxiais 1,4-1,7x1,3-1,7 cm, base atenuada, ápice obtuso, seríceas; estames 10, 7-10 mm de compr., filetes pilosos, anteras rimosas, isomórficas; ovário ca. de $5 \mathrm{~mm}$ de compr., seríceo, estípite ca. de 1,5 mm compr., estilete ca. de $3 \mathrm{~mm}$ compr., estigma peltiforme. Legumes samaróides, $6-6,5 \times 1 \mathrm{~cm}$, elíptico-oblongos a fusiformes, estípite ca. de $2 \mathrm{~mm}$ de compr., base e ápice agudos, tomentoso-ferrugíneos a glabrescentes; sementes 1-3, exariladas.

Material examinado - BRASIL. Minas Gerais: EAVG, trilha 2, IX/2003 (fr.), Filardi et al. 296 (VIC); III/2004 (fl., fr.) e Filardi et al. 451 (VIC); trilha 3, I/ 2003 (fl., fr.), Filardi 158 \& Faria (VIC); II/2003 (fl., fr.) e Filardi et al. 203 (VIC).

RestritaàAmérica doSul(BARNEBY, 1996), apresentase amplamente distribuída no Brasil, onde ocorre em áreas de MataAtlântica (MORIM, 2006), Cerrado (RATTER et al., 2003) e em campos rupestres da Cadeia do Espinhaço (ZAPPI et al., 2003). Na EAVG, a espécie é frequente e restrita a áreas de Cerrado sensu stricto.

9. Pterogyne nitens Tul., Ann. Sci. Nat. Bot., $2^{\circ}$ ser. 20: 140. 1843. Figuras 21-23

Nome popular: Amendoim-bravo

Árvores 9-16 m alt.; ramos lenticelados, puberulentos. Folhas imparipinadas; estípulas caducas; pecíolo $(1,4-) 1,9-3,4(-3,9) \mathrm{cm}$ de compr., puberulento a esparsamente tomentoso; raque (6,5-)12,5-16,6 cm de compr., puberulenta a esparsamente tomentosa, com apêndice terminal; folíolos (5-)9-15, (2-)4-6,8x1-2,5 cm, alternos, elípticos, base obtusa, ápice retuso, glabros. Inflorescências racemosas, pêndulas, pedúnculo 3-6 mm compr., raque 4-6,5 cm de compr., tomentosa. Flores actinomorfas; pedicelo ca. de $3 \mathrm{~mm}$ de compr.; cálice 5laciniado, sépalas 1,8-2x0,8-1 mm, puberulentas; pétalas amareladas, 2,3-2,5x0,5-0,8 mm, base obtusa, ápice obtuso a truncado; estames 10, 2,7-3,2 mm de compr., filetes glabros, anteras rimosas, isomórficas; ovário ca. de $0,3 \mathrm{~mm}$ de compr., seríceo, estípite ca. de 0,3 mm de compr., estilete ca. de 0,2 mm de compr., excêntrico, estigma capitado. Sâmaras, de 4,9-6x1,5-1,9 cm, estípite ca. de 2 mm de compr., base e ápice obtusos, glabras, castanho-claras; região seminífera proximal, ca. $13 \mathrm{~mm}$ de larg., reticulada, ala ca. de $18 \mathrm{~mm}$ de larg., reticulada; monospérmica, semente exarilada.

Material examinado - BRASIL. Minas Gerais: EAVG, trilha 1, II/2003 (fl., fr), Filardi et al. 252 (VIC); trilha 8, IX/2003 (fr.) e Filardi et al. 325 (VIC).

No Brasil, a distribuição de P. nitens é correspondente à “diagonal seca”, formada por áreas de elevada sazonalidade que se estendem do Nordeste ao Sul do país (PRADO e GIBBS, 1993), sendo característica de Florestas Semidecíduas do CentroOeste e Sudeste do Brasil (OLIVEIRA-FILHO e FONTES, 2000). Na EAVG, a espécie é pouco frequente, ocorrendo na área de Cerrado sensu stricto em estágio de regeneração mais avançado e em floresta associada à área de várzea.

10. Senna alata (L.) Roxb., Fl. Indica 2: 349. 1824. Figuras 27-29

Nome popular: Fedegoso-grande, mangeriobagrande

Arbustos ca. 1,6 m alt.; ramos angulosos, glabros. Folhas paripinadas; estípulas lanceoladas, com 8-18 mm de compr.; pecíolo com 1,5-2,2 cm de compr., pulverulento; raque com $30-43 \mathrm{~cm}$ de compr., pulverulenta, nectário cônico entre o par distal de folíolos; folíolos (9-)10-12 pares, 10,3-16,5x(3,8-)4,5-7,6 cm, opostos, oblongos a obovados, base oblíqua, ápice emarginado, face abaxial levemente pilosa sobre as nervuras. Inflorescências racemosas, pedúnculo com 6,5-17 cm de compr., raque com 10-12 cm de compr., glabrescente. Flores zigomorfas; pedicelo ca. de $7 \mathrm{~mm}$ de compr.; 
cálice 5-laciniado, sépalas com 12-14x6-10 mm, petaloides, puberulentas; pétalas amarelas, a centro-adaxial ca. de 20x14 mm, base truncada, ápice obtuso; as lateroadaxiais ca. de 15x14 mm; as abaxiais ca. de 13x11 mm; estames 7, 4 medianos com 12-16 mm de compr., 2 adaxiais de 5,5-9,5 mm de compr., 1 abaxial de 15-20 mm de compr., filetes glabros, anteras poricidas, heteromórficas, 3 estaminódios; ovário ca. de $12 \mathrm{~mm}$ de compr., puberulento, estípite ca. de $4 \mathrm{~mm}$ compr., estilete ca. de $7 \mathrm{~mm}$ de compr., estigma apical. Legumes de 13,3-15x2,3-3 cm, oblongos, quadrangulares, alados, estípite ca. de 6 mm de compr., base obtusa, ápice agudo, glabros, castanho-escuros a enegrecidos; 27-43 sementes, exariladas.

Material examinado - BRASIL. Minas Gerais: EAVG, trilha 7, V/2004 (fl., fr.), Filardi et al. 522 (VIC); V/2005 (fl., fr.), Filardi et al. 590 (VIC).

A espécie apresenta-se amplamente distribuída na América (ILDIS, 2007), assim como no Brasil, onde ocorre em formações campestres, frequentemente em áreas alagadas (IRWIN e BARNEBY, 1982). Na EAVG, ocorre de forma expressiva nas áreas próximas à várzea.

11. Senna macranthera (Collad.) H. S. Irwin \& Barneby, Mem. New York Bot. Gard. 35 (1): 181.1982. Figuras 30-31

\section{Nome popular: Fedegoso}

Arvoretas com 2,5-3,5 m de alt.; ramos angulosos, tomentosos. Folhas paripinadas; estípulas lineares, de 3-15 mm de compr., caducas; pecíolo com 1,7-3,5 (-4) cm de compr., densamente tomentoso; raque com 1,6-3,5 cm de compr., densamente tomentosa, nectários cônicos ou fusiformes entre o par proximal de folíolos e ao lado dos pulvínulos distais; folíolos 2 pares $(4,8) 5,8$ $11(-12,7) \times(-2,8)$ de $3,5-4,8 \mathrm{~cm}$, opostos, obovados, base oblíqua, ápice agudo, face adaxial glabrescente, face abaxial esparsamente tomentosa. Inflorescências em panículas racemosas, pedúnculo 3,2-3,7 mm de compr., raque com $7-8 \mathrm{~cm}$ de compr., tomentosa. Flores zigomorfas; pedicelo com 3,2-4,7 cm de compr.; cálice 5-laciniado, sépalas 7-9x4-5 mm, seríceas; pétalas amarelas; a centroadaxial de 3,6-3,8x2,3-2,5 cm, as latero-adaxiais e abaxiais de 3,2-3,6x1,8-2,2 cm, base aguda, ápice obtuso, puberulentas; estames 7, 4 medianos de 5,5-13 mm de compr., 3 abaxiais com 11-23 mm de compr., filetes puberulentos, anteras poricidas, heteromórficas, 3 estaminódios; ovário ca. de $3 \mathrm{~cm}$ de compr., tomentoso, estípite ca. de $4 \mathrm{~mm}$ de compr., estilete com 3-5 mm de compr., estigma crestado. Frutos não observados.

Material examinado - BRASIL. Minas Gerais: EAVG, trilha 1, II/2003 (fl.), Filardi et al. 247 (VIC); trilha 2, III/2004 (fl.) e Filardi et al. 441 (VIC).

A espécie conta com cinco variedades citadas para o Brasil (IRWIN e BARNEBY, 1982). O material estudado apresentou características vegetativas intermediárias entre a var. macranthera e a var. micans, não sendo aqui definida sua categoria infra específica. Nativa da América do Sul, no Brasil, ocorre na Bahia, Ceará, Espírito Santo, Goiás, Minas Gerais, Piauí, Rio de Janeiro e São Paulo, ocupando áreas de Mata Atlântica, Caatinga, Cerrado (IRWIN e BARNEBY, 1982) e campos rupestres (ZAPPI et al., 2003). Na EAVG, a espécie é restrita e frequente nas formações de Cerrado sensu stricto.

12. Senna pendula var. glabrata (Vogel) H. S. Irwin \& Barneby, Mem. New York Bot. Gard. 35 (1): 382-383. 1982. Figuras 32-33

Nome popular: Cássia, fedegoso, canudo-de-pito

Arbustos com 3-4 m de alt.; ramos cilíndricos, canaliculados, puberulentos. Folhas paripinadas; estípulas linear-lanceoladas, ca. de $1 \mathrm{~mm}$ de compr., caducas; pecíolo (1,8-)2-3,4(-3,8) cm de compr., seríceo a glabrescente; raque (1,5-)2-3(-3,6) cm de compr., serícea a glabrescente, nectário cônico ou clavado entre o par proximal de folíolos; folíolos 4-5 pares $(1,4-) 2,4-$ $3,5(-4,4) \times 1-1,8 \mathrm{~cm}$, opostos, obovados, base oblíqua, ápice obtuso a retuso, face adaxial com tricomas esparsos, glabrescente, face abaxial puberulenta, tricomas sobre a nervura mediana. Inflorescências racemosas, pedúnculo com 3,5-4 cm de compr., raque com 3-5,3 cm de compr., serícea a glabrescente. Flores zigomorfas; pedicelo ca. de $15 \mathrm{~mm}$ de compr.; cálice 5-laciniado, sépalas 6-14x4-10 mm; pétalas amarelas; a centro-adaxial ca. $16 \times 18 \mathrm{~mm}$; as latero-adaxiais ca. de $18 \times 14 \mathrm{~mm}$, base atenuada; as abaxiais ca. de 20x11 mm, base atenuada; estames 7, 4 medianos 5-11 mm de compr., 1 abaxial central 7-13 mm de compr., 2 abaxiais laterais 12,5-30 $\mathrm{mm}$ de compr., filetes glabros, anteras poricidas, heteromórficas, 3 estaminódios; ovário ca. de $2 \mathrm{~cm}$ de compr., glabro, estípite ca. de $4 \mathrm{~mm}$ de compr., estilete ca. de $8 \mathrm{~mm}$ de compr., estigma truncado. Frutos não observados.

R. Árvore, Viçosa-MG, v.33, n.6, p.1071-1084, 2009 
Material examinado - BRASIL. Minas Gerais: EAVG, trilha 1, V/2005 (fl), Filardi et al. 586 (VIC); trilha 7, V/2005 (fl), Filardi $632 \&$ Garcia (VIC); trilha 8, V/2004 (fl.), Filardi et al. 505 (VIC); Filardi et al. 559 (VIC).

A variedade glabrata é restrita ao Paraguai e ao Brasil, onde apresenta ampla distribuição, ocupando preferencialmente áreas de Cerrado do Nordeste ao Sul do país, não sendo relatada em regiões litorâneas (IRWIN e BARNEBY, 1982). Na EAVG, o táxon ocorre tanto em Cerrado sensu stricto quanto em florestas associadas à área de várzea.

13. Senna silvestris var. bifaria $H$. S. Irwin \& Barneby, Mem. New York Bot. Gard. 35 (1): 94. 1982. Figuras 34-36

Nome popular: Amendoim-do-campo, avelão

Árvores com 4,5-5 m de alt.; ramos cilíndricos a levemente angulosos, canaliculados, lenticelados, puberulentos. Folhas paripinadas; estípulas lineares, ca. de $4 \mathrm{~mm}$ de compr., caducas; pecíolo (2,6-)3-4 $(-5,5) \mathrm{cm}$ de compr., puberulento a esparsamente tomentoso; raque (6-)9,8-13 cm de compr., puberulenta a esparsamente tomentosa; folíolos (5-)7-8 pares, (3-)3,5-7,5(-8)x1,8-4 cm, opostos, elípticos a oblongos, base obtusa, ápice agudo, face adaxial com tricomas sobre as nervuras, face abaxial tomentosa. Inflorescências em panículas racemosas corimbiformes, pedúnculo com 1,2-2,4 cm compr., raque com 3,5$6,8 \mathrm{~cm}$ de compr., puberulenta. Flores zigomorfas; pedicelo com 2,4-2,8 cm de compr.; cálice 5-laciniado, sépalas com 5-12x3-11 mm, glabras; pétalas amarelas; a centro-adaxial de 18-19x17-20 mm, base truncada, ápice emarginado; as latero-adaxiais e abaxiais de 14-16x16-18 mm, base truncada, ápice obtuso a emarginado; estames 7, 4 medianos com 5-9,5 mm de compr., 1 abaxial central com 8,5-14,5 mm de compr., 2 abaxiais laterais com 10,5-17,5 mm de compr., filetes glabros, anteras poricidas, heteromórficas, 3 estaminódios; ovário ca. de $10 \mathrm{~mm}$ de compr., esparsamente velutino, estípite ca. de $3 \mathrm{~mm}$ de compr., estilete ca. de $2 \mathrm{~mm}$ de compr., estigma lateral, barbelado. Legumes com 10,3-14,5x 1,8-2,6 cm, oblongos, estípite ca. de $6 \mathrm{~mm}$ de compr., base obtusa, ápice agudo, glabros, castanho-avermelhados, margem das valvas espessada, transversalmente reticulados; 28-36 sementes, exariladas.

R. Árvore, Viçosa-MG, v.33, n.6, p.1071-1084, 2009
Material examinado - BRASIL. Minas Gerais: EAVG, trilha 2, III/2004 (fl.), Filardi et al. 431 (VIC); trilha 7, II/2003 (fl., fr.); Filardi et al. 265 (VIC).

A variedade é restrita ao Brasil e ocorre em áreas de Cerrado, entre 400 e $1.000 \mathrm{~m}$ de altitude, nos Estados de Goiás, Mato Grosso, Minas Gerais e São Paulo (IRWIN e BARNEBY, 1982), fazendo parte da flora lenhosa peculiar do bioma (RIZZINI, 1963). Na EAVG, o táxon é pouco frequente, mas ocupa tanto áreas de Cerrado sensu stricto quanto de floresta associada à várzea.

14. Tachigali rubiginosa (Mart. ex Tul.) OliveiraFilho, Cat. Árvores Nativas Minas Gerais 141. 2006. Figuras 24-26

Sclerolobium paniculatum var. rubiginosum (Mart. ex Tul.) Benth., Fl. bras. 15 (2): 47.1870.

Nome popular: Carvoeiro, tachi-branco

Árvores ca. de $12 \mathrm{~m}$ de alt.; ramos cilíndricos, levemente canaliculados, tomentoso-ferrugíneos. Folhas paripinadas; estípulas lanceoladas, ca. de $2 \mathrm{~mm}$ de compr.; pecíolo de 4,6-6 cm de compr., velutino; raque (6,5-)14-19,5 cm de compr., velutina; folíolos (3-)5-7 pares, (6-)7,8-11x2,5-4 cm, opostos, oblongos a elípticos, base oblíqua, ápice caudado, face adaxial glabrescente, face abaxial velutina. Inflorescências em panículas racemosas, pedúnculo de 5-12 mm compr., raque 5,8$8 \mathrm{~cm}$ compr., velutina. Flores actinomorfas; pedicelo 3-4 mm compr.; cálice 5-laciniado, sépalas de 3-3,5x1,82,5 mm, seríceas; pétalas creme, $3-4 \times 0,1 \mathrm{~mm}$, base truncada, ápice obtuso; estames 10, 5,5-6,5 mm de compr., filetes pilosos, anteras rimosas, isomórficas; ovário ca. de $2 \mathrm{~mm}$ de compr., seríceo, estípite ca. de 0,8 $\mathrm{mm}$ de compr., estilete ca. de 2,5 mm de compr., geniculado, estigma crestado. Frutos não observados.

Material examinado - BRASIL. Minas Gerais: EAVG, trilha 2, IX/2003 (fl.), Filardi et al. 349 (VIC).

A espécie ocorre no Sudeste do Brasil (SILVA e LIMA, 2007), onde é citada em áreas de Cerrado, principalmente no Estado de Minas Gerais (DWYER, 1957), estando entre as espécies lenhosas características do bioma (RIZZINI, 1963; RATTER et al., 2003). Na EAVG, a espécie é pouco frequente e restrita a apenas uma das áreas de Cerrado sensu stricto. 
Fonte: Ilustrações de Reinaldo A. Pinto.

Source: Illustrated by Reinaldo A. Pinto.

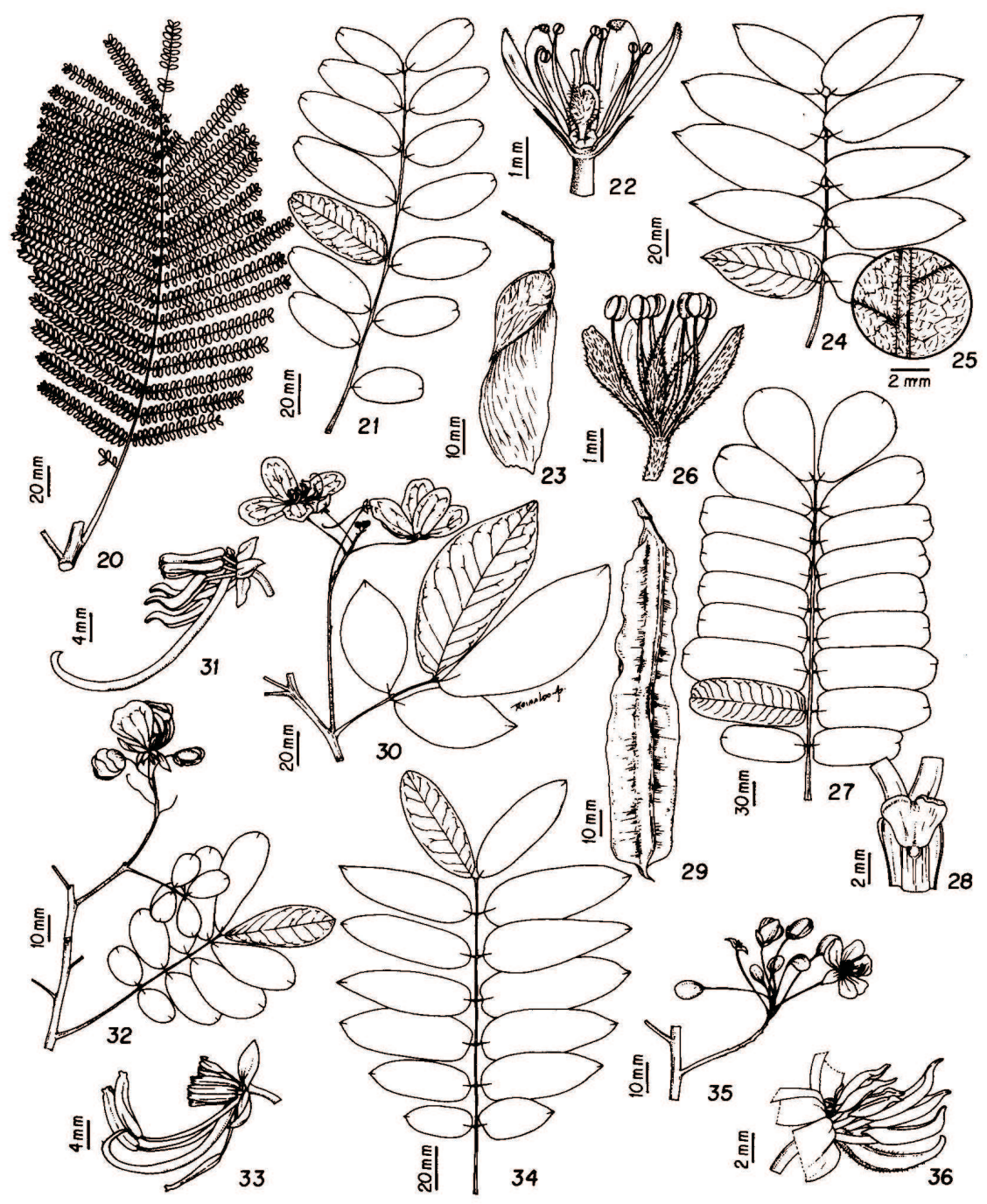

Figura 2-Peltophorum dubium var. dubium: 20. Folha (Filardi et al. 451). Figuras 21-23. Pterogyne nitens: 21. Folha, 22. Flor em corte longitudinal (Filardi et al. 252), 23. Fruto (Filardi et al. 325). Figuras 24-26. Tachigali rubiginosa: 24. Folha, 25. Indumento na face abaxial do folíolo, 26. Flor em corte longitudinal (Filardi et al. 349). Figuras 27-29. Senna alata: 27. Folha, 28. Nectário extrafloral, 29. Fruto (Filardi et al. 522). Figuras 30-31. Senna macranthera: 30. Ramo floral (Filardi et al. 247), 31. Androceu e gineceu (Filardi et al. 441). Figuras 32-33. Senna pendula var. glabrata: 32. Ramo floral (Filardi et al. 505), 33. Androceu e gineceu (Filardi et al. 559). Figuras 34-36. Senna silvestris var. bifaria: 34. Folha (Filardi et al. 265), 35. Inflorescência, 36. Androceu e gineceu (Filardi et al. 431).

Figure 2-Peltophorum dubium var. dubium: 20. Leaf(Filardi et al. 451). Figures 21-23. Pterogyne nitens: 21. Leaf, 22. Flower in longitudinal view (Filardi et al. 252), 23. Fruit (Filardi et al. 325). Figures 24-26. Tachigali rubiginosa: 24. Leaf, 25. Indummentum of leaflet abaxial face, 26. Flower in longitudinal view (Filardi et al. 349). Figures 27-29. Senna alata: 27. Leaf, 28. Extrafloral nectaries, 29. Fruit (Filardi et al. 522). Figures 30-31. Senna macranthera: 30. Floral branch (Filardi et al. 247), 31. Androecium and gynoecium (Filardi et al. 441). Figures 32-33. Senna pendula var. glabrata: 32. Floral branch (Filardi et al. 505), 33. Androecium and gynoecium (Filardi et al. 559). Figures 34-36. Senna silvestris var. bifaria: 34. Leaf (Filardi et al. 265), 35. Inflorescence, 36. Androecium and gynoecium (Filardi et al. 431). 


\subsection{Considerações Finais}

Na EAVG, as trilhas 1 e 2, localizadas em áreas de Cerrado sensu stricto, foram as com maior riqueza em espécies, sete e nove, respectivamente, seguidas pela trilha 3 (4 spp.), estabelecida na mesma fisionomia. $\mathrm{Na}$ trilha 4, que representa a área mais alterada de Cerrado sensu stricto, assim como nas manchas de Cerradão (trilhas 5 e 6), não foram observados representantes lenhosos de Caesalpinioideae. As áreas de Floresta Semidecidual localizadas próximas à área de várzea (trilhas 7 e 8) reuniram três espécies cada uma, enquanto a trilha 9, na margem mineira do reservatório, apresentou apenas uma espécie, não sendo observados representantes da subfamília na trilha 10 , localizada na margem paulista do reservatório.

Entre os táxons estudados, cinco ocorrem apenas no Brasil, sendo Bauhinia rufa, Diptychandra aurantiaca subsp. aurantiaca, Senna silvestris var. bifaria e Tachigali rubiginosa são característicos do Cerrado. Dos oito táxons restritos à América do Sul, Dimorphandra mollis e Senna pendula var. glabrata ocorrem frequentemente no Cerrado, enquanto Apuleia leiocarpa, Copaifera langsdorffii e Pterogyne nitens são consideradas características de Florestas Semidecíduas do Sudeste do Brasil.

A presença expressiva de espécies de Caesalpinioideae pertencentes à flora lenhosa peculiar do Cerrado, bem como de espécies características de Florestas Semidecíduas, indica que a área de estudo, após 30 anos de regeneração natural, encontra-se em franco processo de sucessão, ressaltando sua importância para o conhecimento e preservação da flora e da fauna a ela associada, no Triângulo Mineiro.

\section{AGRADECIMENTOS}

Este trabalho é parte integrante do estudo da flora da Estação Ambiental de Volta Grande (Convênio $\mathrm{n}^{\circ} 315$, registro P\&D 042 - SIF/CEMIG/ANEEL). Agradecimentos em especial à EAVG, pela estrutura física concedida e atenção de seus funcionários; ao Reinaldo A. Pinto, pelas ilustrações; e aos amigos Sebastião L. Faria e Carlos Matheus S. Paixão, pelo auxílio nos trabalhos de campo.

\section{REFERÊNCIAS}

ARAÚJO, F. S. et al. Florística da vegetação arbustivo-arbórea colonizadora de uma área degradada por mineração de caulim em Brás Pires, MG. Revista Árvore, v.29, n.6, p.983-992, 2005.
BARNEBY, R. C. Neotropical Fabales at NY: asides and oversights. Brittonia, v.48, n.2, p.174-187, 1996.

BARROSO, G. M. et al. Frutos e sementes: morfologia aplicada à sistemática de dicotiledôneas. Viçosa, MG: Universidade Federal de Viçosa, 1999. 443p.

BORTOLUZZI, R. L. C. et al. LeguminosaePapilionoideae no Parque Estadual do Rio Doce, Minas Gerais, Brasil. II: árvores e arbustos escandentes. Acta Botanica Brasilica, v.18, n.1, p.49-71, 2004.

BRANDÃO, M. et al. Cobertura vegetal do município de Sete Lagoas, MG. Daphne, v.3, n.2, p.21-38, 1993.

BRANDÃO, M. et al. Município de Uberaba, MG: cobertura vegetal e composição florística.

Daphne, v.5, n.1, p.19-39, 1995.

BRANDÃO, M.; GAVILANES, M. L.; ARAÚJO, M. G. Cobertura vegetal do município de Prudente de Morais, MG. Daphne, v.6, n.2, p.40-58, 1996.

COUTINHO, L. M. O bioma do cerrado. In: KLEIN, A. L. (Ed.). Eugen warming e o cerrado brasileiro: um século depois. São Paulo: Universidade Estadual de São Paulo, 2002. p.77-92.

\section{CENTRO DE PREVISÃO DE TEMPO E ESTUDOS CLIMÁTICOS/INSTITUTO NACIONAL DE PESQUISAS ESPACIAIS - CPETEC/INPE. http:// www.cptec.inpe.br/clima/monit/ monitor_brasil.shtml. Acesso: março a dezembro 2006}

DRUMOMOND, G. M. et al. Biodiversidade em Minas Gerais: um atlas para sua conservação. Belo Horizonte: Fundação Biodiversitas, 2005. 222p.

DURIGAN, G. et al. Plantas do cerrado paulista: imagens de uma paisagem ameaçada. São Paulo: Páginas \& Letras, 2004. 475p.

DUTRA, V. F.; GARCIA, F. C. P.; LIMA, H. C. Caesalpiniodeae (Leguminosae) nos Campos Rupestres do Parque Estadual do Itacolomi, MG, Brasil. Acta Botanica Brasilica, v.22, NUMERO, p.547-558, 2008. 
DWYER, J. D. The Central American, West Indian and S. American species of Copaifera

(Caesalpiniaceae). Brittonia, v.7, n.3, p.143-172, 1951.

DWYER, J. D. The American genus Sclerolobium Vogel (Caesalpiniaceae). Lloydia, v.20, n.2, p.67$118,1957$.

EITEN, G. The cerrado vegetation of Brazil. Botanical Review, v.38, n.2, p.201-341, 1972.

FIDALGO, O.; BONONI, V. L. R. Técnicas de coleta, preservação e herborização do material botânico. São Paulo: Instituto de Botânica, 1984.61p.

FILARDI, F. L. R. et al. Papilionoideae (Leguminosae) do Parque Nacional da Serra da Canastra, Minas Gerais, Brasil. Hoehnea, v.34, n.3, p.383-408, 2007a.

FILARDI, F. L. R.; GARCIA, F. C. P.; CARVALHOOKANO, R. M. Espécies lenhosas de Papilionoideae (Leguminosae) na Estação Ambiental de Volta Grande, Minas Gerais, Brasil. Rodriguésia, v.58, n.2, p.363-378, 2007b.

INTERNATIONAL LEGUME DATABASE AND INFORMATION SCIENCE - ILDIS. Disponível em: < www.ildis.org > Acesso: março a outubro 2007.

IRWIN, H. S.; BARNEBY, R. C. The american cassiinae: a synoptical revision of leguminosae tribe cassieae subtribe cassiinae in the new world. Memoirs of the New York Botanical Garden, v.35, n.1/2, p.1-918, 1982.

LEE, Y. T.; LANGENHEIM, J. H. Systematics of the genus Hymenaea L. (Leg. Caesalpinioideae, Detarieae). University of California Publications in Botany, v.69, p.1-109, 1975.

LEWIS, G. P. Legumes of Bahia. Kew: Royal Botanic Gardens, 1987.369p.

LIMA, H. C.; CARVALHO, A. M.; COSTA, C. G. Estudo taxonômico do gênero Diptychandra Tulsane (Leguminosae-Caesalpinioideae). In: CONGRESSO NACIONAL DE BOTÂNICA, 35. 1987, Curitiba. Anais... Curitiba: Sociedade Botânica do Brasil, 1987. p.175-185.

LEWIS, G. P. et al. Legumes of the world. Kew: Royal Botanic Gardens, 2005. 577p.
LIMA, L. C. P.; GARCIA, F. C. P.; SARTORI, A. L. B. Leguminosae nas florestas estacionais do Parque Estadual do Itacolomi, Minas Gerais, Brasil: ervas, arbustos, subarbustos, lianas e trepadeiras. Rodriguésia, v.58, n.2, p.331-358, 2007.

MEIRA NETO, J. A. A.; SAPORETTI JÚNIOR, A. W. Parâmetros fitossociológicos de um cerrado no Parque Nacional da Serra do Cipó, MG. Revista Árvore, v.26, n.5, p.645-648, 2002.

MENDONÇA FILHO, C. V. Braúna, angico, jacarandá e outras leguminosas de Mata Atlântica - Estação Biológica de Caratinga, Minas Gerais. Belo Horizonte: Fundação Botânica Margaret Mee e Fundação Biodiversitas, 1996. 100p.

MENDONÇA, R. C. et al. Flora vascular do cerrado. In: SANO, M.; ALMEIDA, S.P. (Eds.). Cerrado: ambiente e flora. Planaltina: EmbrapaCPAC, 1998. p.287-556.

MORIM, M. P. Leguminosae arbustivas e arbóreas da Floresta Atlântica do Parque Nacional do Itatiaia, Sudeste do Brasil: padrões de distribuição. Rodriguésia, v.57, n.1, p.27-45, 2006.

MYERS, N. et al. Biodiversity hotspots for conservation priorities. Nature, v.403, p.853858,2000

OLIVEIRA-FILHO, A. T. Catálogo de árvores nativas de Minas Gerais: mapeamento e inventário florístico da flora nativa e dos reflorestamentos de Minas Gerais. Lavras: Universidade Federal de Lavras, 2006. 423p.

OLIVEIRA-FILHO, A. T.; FONTES, M. A. L. Patterns of floristic differentiation among Atlantic Forests in southeastern Brazil and the influence of climate. Biotropica, v.32, n.4b, p.793-810, 2000.

POLHILL, R. M.; RAVEN, P. H. Advances in legume systematics. Kew: Royal Botanic Gardens, 1981. 1049p.

PRADO, D. E.; GIBBS, P. E. Patterns of species distribution in the dry seasonal forests of South America. Annals of Missouri Botanical Garden, v.80, NUMERO, p.902-927, 1993.

R. Árvore, Viçosa-MG, v.33, n.6, p.1071-1084, 2009 
QUEIROZ, L. P. Flora de Grão Mogol, Minas Gerais: Leguminosae. Boletim de Botânica da Universidade de São Paulo, v.22, NUMERO, p.213-265, 2004.

RADFORD, A. E. et al. Vascular plant systematics. New York: Harper \& Row, 1974. 891p.

RATTER, J. A.; BRIDGEWATER, S.; RIBEIRO, J. F. Analysis of the floristic composition of the Brazilian Cerrado vegetation III. Comparison of the woody vegetation of 376 areas. Edinburgh Journal of Botany, v.60, n.1, p.57-109, 2003.

RIZZINI, C. T. A flora do cerrado: análise florística das savanas centrais. In: RIZZINI, C.T. (Ed.). Simpósio sobre o cerrado. São Paulo: EDUSP, 1963. p.127-177.

RODRIGUES, I. M. C.; GARCIA, F. C. P.

Papilionoideae (Leguminosae) arbóreas e lianas na Estação de Pesquisa, Treinamento e Educação Ambiental (EPTEA), Mata do Paraíso, Viçosa, Zona da Mata mineira. Revista Árvore, v.31, n.3, p.521-532, 2007.
SAPORETTI JÚNIOR, A. W.; MEIRA NETO, J. A. A.; ALMADO, R. P. Fitossociologia de Cerrado Sensu Stricto no município de Abaeté, MG.

Revista Árvore, v.27, n.3, p.413-419, 2003.

SILVA, L. F. G.; LIMA, H. C. Mudanças nomenclaturais no gênero Tachigali Aubl. (Leguminosae - Caesalpinioideae) no Brasil. Rodriguésia, v.58, n.2, p.397-401, 2007.

SILVA, M. F. Dimorphandra (Caesalpiniaceae). Flora Neotropica, v.44, n.1, p.1-128, 1986.

SPRENT, J. I. Nodulation in legumes. Kew: Royal Botanic Gardens, 2001.146p.

VAZ, A. M. S. F.; TOZZI, A. M. G. A. Bauhinia ser. Cansenia (Leguminosae: Caesalpinioideae) no Brasil. Rodriguésia, v.54, n.83, p.55-143, 2003.

ZAPPI, D. C. et al. Lista das plantas vasculares de Catolés, Chapada Diamantina, Bahia, Brasil. Boletim de Botânica da Universidade de São Paulo, v.21, n.2, p.345-389, 2003. 